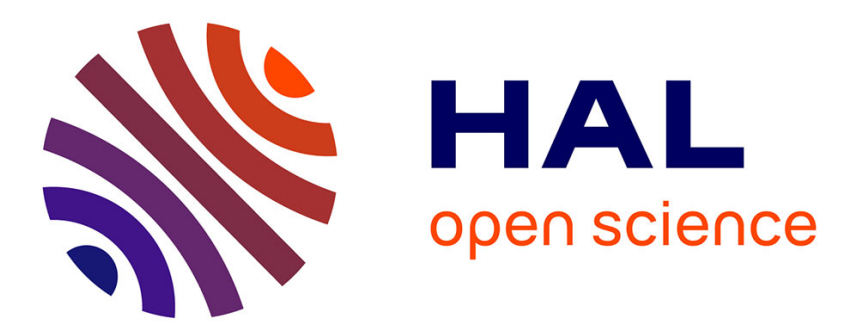

\title{
Managing radical innovation as an innovative design process: generative constraints and cumulative sets of rules
}

\author{
Pierre-Antoine Arrighi, Pascal Le Masson, Benoit Weil
}

\section{To cite this version:}

Pierre-Antoine Arrighi, Pascal Le Masson, Benoit Weil. Managing radical innovation as an innovative design process: generative constraints and cumulative sets of rules. Creativity and Innovation Management, 2015, 24 (3), pp.373-390. 10.1111/caim.12135 . hal-01199932

\section{HAL Id: hal-01199932}

https://hal-mines-paristech.archives-ouvertes.fr/hal-01199932

Submitted on 17 Sep 2015

HAL is a multi-disciplinary open access archive for the deposit and dissemination of scientific research documents, whether they are published or not. The documents may come from teaching and research institutions in France or abroad, or from public or private research centers.
L'archive ouverte pluridisciplinaire HAL, est destinée au dépôt et à la diffusion de documents scientifiques de niveau recherche, publiés ou non, émanant des établissements d'enseignement et de recherche français ou étrangers, des laboratoires publics ou privés. 
Managing radical innovation as an innovative design process: generative constraints and cumulative sets of rules

\author{
Authors: Arrighi, Pierre-Antoine ;Le Masson, Pascal ; Weil, Benoit
}

\begin{abstract}
This paper focuses on the organization of design processes and the difficulty of simultaneously achieving control and exploration while aiming to achieve radical innovation. After a first generation of works that tended to oppose NPD processes (with controlled convergence and very limited exploration) to Innovation processes (with poorly controlled convergence and random (uncontrolled) exploration, the new generation of works proposed ways to combine control and convergence either through concept shift or through stable architectures. Relying a generic analytical framework (design space / value management) it appears that each model makes restrictive hypotheses (respectively smart leadership or stable architecture) to address two critical questions: Q1. How can one increase the efficiency of exploration? Q2. How can one ensure forms of cumulative convergence? Relying on the ame analytical framework we analyze two cases that explore the unknown in a controlled way and still don't correspond two either of the two models. We show that these two anomalies and the two models actually have two critical features in common: a focus on generative constraint and a logic of cumulative design rules. As a consequence these two features might generic to several processes where teams have to explore the unknown and still have to keep a rigorous control of exploration and convergence.
\end{abstract}

\title{
INTRODUCTION
}

Modern product design teams have to develop new, creativeproducts that integrate original features that arehighly new to their technical or market experience. These radical or discontinuous innovations (Veryzer 1998)require development processes that go beyond NPD practices based upon optimization and planning. They require, for instance, exploration, "try and learn"(Sommer et Loch 2004), learning and new competence management (Christianson et al. 2005) or creativity (Badke-Schaub, Goldschmidt et Meijer 2010). These development processes have inspired specific research works. In the 1990s, a first generation of research expressed and analyzed a strong trade-off between the monitoring of the creative breakthrough (meaning its control) and the capacity to explore and learn during the process. New product development processes have proven efficient for control and risk management(Clark et Fujimoto 1991),but these processeslack flexibility and are negatively related to innovation and creativity productivity (Harmancioglu et al. 2007). Research on radical innovation(Van de Ven et al. 1999)tends to demonstrate that deep and durable explorations follow ill-defined processes and that convergence control is difficult. 
To address these issues, a second generation of theories attempted to bridge these two tendencies by providing simultaneously for control and exploration. We can identify two streams of research. On the one hand, in the "modular process" model (Sanchez et Mahoney 1996; MacCormack, Verganti et Iansiti 2001), control is guaranteed by the architecture of the product. In this model, explorationand creativity can occur at the level of "modular components" that are loosely coupled to the platform (Gawer 2009). Hence, the product architecture "monitors" the exploration, both framing and supporting it. On the other hand, in the concept shift process model (Seidel, 2007), designers canexplore a product concept not only in the fuzzy front-end phases but also late in the process, achievinga concept shift by modifying the concept's components. In this case, convergence and divergence dependupon leadership and team practices. The first model relies on a "structural hypothesis" (a stable structure, the architecture of the product, warrants the exploration process); the second model on a "leadership hypothesis" (the quality of leaders warrants the quality of the initial concepts and the subsequent exploration).

Beyond their differences, these two models have a lot in common. In particular, we will show that they both rely on a strong "shift" in the approach of exploration monitoring. Whereas the first generation of works tended to limit monitoring and management to decision-making and selection of the "best alternative", the modular process or the concept shift approaches consider that process management also includes support forthe divergent, exploratory and creative part of the process. This is in line with recent works on design processes and cognitive processes that show that managing creative innovative design processes actually consists in managing "de-fixation" (Archer 1965; Jansson et Smith 1991; Bonnardel et Marmèche 2004; Agogué et al. 2014; Le Masson, Hatchuel et Weil 2011). Instead of managing planning and selection, the design process tends to manage efficient divergence and knowledge accumulation. In this design perspective, the management of radical (or creative) innovation process actually raises two questions that we will address in this paper: Q1: how to manage the process to prevent "fixation"? andQ2: how to organize a cumulative process linking the multiple exploratory phases? We show more specifically that radical innovation process management actually requires a capacity to address "generative constraints" (i.e., identify critical issue and work them out in a creative way (Result 1) and to accumulate the knowledge acquired in the exploratory phases into a coherent set of rules (Result 2).

To answer these research questions, we first analyze how the two models, modular and concept shift processes, already propose partial answers; we also show that these two models seem to rely on specific conditions (product structure or leadership quality). To generalize these models and underline the deep similarities between them, we need to discuss theselimiting conditions. To this end, we rely upon case studies to exhibit two counterexamples that show that these conditions are actually unnecessary. Hence, we show that it is possible to generalize the last two models and to see a deep correspondence between them.

To do this, we identified two relevant cases thatappear at first to very closelyresemble the two archetypal models: 1) a first case is very close to a 
prototypical"modular process" because there are many "constraints" (just like a modular process is constrained by the product architecture), and we show that these constraints will actually be the support for a creative solution (and in particular, these constraints lead to an innovative product architecture); 2) the second case isvery close to a free concept shift (because people are able to strongly diverge from the initial concept), and we show that this shift actually relies upon technical tools to focus exploration and to accumulate the results. To follow the design process, we use a novel way of analyzing it. We tracked the data generated by computer-aided design (CAD) tools. These data were supplementedby interviews with the designers for better understanding and verification.

We first introduce the theoretical background that leads to a gap in research and theassociated research questions. We then detail our method with a presentation of the cases studied, data collected, and interviews conducted. Then, the performance of the processes and how these processes are related to the existing literature are analyzed, the results are discussed, and the conclusions are presented.

\section{THE TENSION BETWEEN CONTROL AND EXPLORATION IN INNOVATION PROCESSES \\ The difficulty of reachingand monitoringradical innovation}

Because radical or discontinuous innovations play an important role in building competitive advantage and can contribute significantly to a firm's growth and profitability, increasing attention has been paid to innovation management at a time when businesses face severe competition that new product development (NPD) solutions fail to fully address(Cooper et Kleinschmidt 1993).Much of the effort to improve NPD has focused on the process as it relates to product improvements. As formulated by Utterback(Utterback et Abernathy 1975)forty years ago, there are drastic inconsistencies between activities focused on productivity improvements and cost reductions and those focused on innovation and flexibility. However, both typesof activities are important for firms' survival.

Radical innovation is occasionally referred to as discontinuous innovation, in opposition to incremental innovation. We follow the definition given by Veryzer (1998).Adiscontinuous innovation is a (strong) change of product capability and technological capability, i.e., the product is commercially discontinuous and/or technologically discontinuous. This definition accounts both for changes in the benefits of the products as perceived or experienced by the customers/users experience and/or changes in the technologies used to design the product. The product contains a "creative" part in the sense that it is original (different from the other products) from commercial or from technological point of view.

A literature review of two specific generations of design process models and recommendations will illustrate the strong rise of radical innovation research and leading propositions for achieving it with success.

In the 1990s, two main tendencies in the literature could be identified.The first was the formulation of a sequential and determined process, the NPDprocess, which 
isnow widely recognized as a key to corporate prosperity(Clark et Fujimoto 1991). The artificial division of the process provides management with a quality control structure in which each "gate" represents an opportunity to recognize and stop the progress of a failing project. When the criteria for passing each gate are chosen wisely, following this prescribed process is one way of assuring the quality of the resulting product (Ulrich et Eppinger 2008).However, Cooper (Cooper 1994), who coined the concept of a "Stage-Gate" process, argues there are many practical weaknesses to this form of tight control.The system can be inefficient such that projects must wait at a gate until all necessary activities have been completed. The overlapping of stages is impossible in most cases, although this overlap is often desirable when radical innovation is needed. Modularity is even more difficult to consider.There can be high bureaucratic overheads at each gate, and the individual project perspective means there is little provision for managing the division of resources across a portfolio.In the end, the Stage-Gateprocess is said to result in lower risk, immediate reward, and incremental project development (McDermott et O'Connor 2002), but it is negatively related to innovation productivity (Harmancioglu et al. 2007). Furthermore, Christiansen andVarnes(Christiansen et Varnes 2009)have shown that, despite their claims, many organizations do notactually use Stage-Gate processes.

Scholars havealso focused on stories of breakthrough innovations. In "The Innovation Journey"(Van de Ven et al. 1999), the design process is described as an innovation journey in whichpractitioners are mostly driven by seemingly chaotic events.This journey is also highly unpredictable and uncontrollable because a sequence of chance "blind" events cannot be anticipated. The authors observed an orderly periodic progression of stages or phases. As a result, the authorshold that no theory could reach the precision necessary to advise managers on exactly what to do and how an innovation will turn out or even how to evaluate its risks or potential outcomes. In the end, the innovation process as described in the "innovation journey" is neither sequential nor a matter of random trialanderror; rather, it should be characterized as a "nonlinear dynamic system"(Cheng et Ven 1996). This type of process can lead to radical innovation, as shown by the results of a cochlear implant case study, but they are extremely complex to manage and can require very long developments (15 years in the study case) for the program to reach full growth.

Hence, this literature underlines a tension between the managerial logic of decision and control on the one hand and the creative logic of exploration required for radical innovation on the other hand.

\section{Modularity and concept shifts:A good fit for managing radical innovation}

In a second generation of works, some scholars have studied the apparent contradiction between control and exploration in radical innovation processes. Instead of considering control and explorationasopposing entities, they have proposed ways of combining them. Two approaches have been identifiedto achieve this goal.

\section{Modularity}


Sanchez and Mahoney (Sanchez et Mahoney 1996) proposed moving from a sequential process to a more modular way of designing products. As a first step, they propose implementing earlier development constraints and changing the organization from sequential and overlapping problemsolving to modular organizationof the product development process. This is the ideal organization with which to address modular product architecture(Sanchez 1995).In modular product design, standardized interfaces among components are specified to allow for a range of variationsin components to be substituted into the product architecture (Baldwin and Woodard, 2008). The product architecture must optimize the operating performance of the product yet also facilitate making changes to the product design as new information emerges (MacCormack, Verganti et Iansiti 2001). This flexibility is supported by modular components, which are components whose interface characteristics are within the range of variations allowed by modular product architecture. This flexible process is characterized by the ability to generate and respond to new information for a longer portion of a development cycle.Product variations can be leveraged by substituting (Garud et Kumaraswamy 1993) different modular components into the product architecture without having to redesign other components. This loose coupling of component designs within modular product architecture allows the "mixing and matching" of modular components to give a potentially large number of product variations distinctive functionalities, features, and/or performance levels (Sanchez 1995).The high degree of independence or "loose coupling" is also critical for designers to bring about radical innovation by working on the componentsthat are the most flexible in the architecture.

A modular product architecture provides a form of embedded coordination that greatly reduces the need for the overt exercise of managerial authority to achieve coordination of development processes. Processes for learning at both the architectural and component levels become more efficient. This process requires that component development begins when the architecture is defined, therefore the revision of an already specified architecture is no longer possible at the module development stage.

\section{Fuzzyfront-end and concept shift}

Another approach to reach radical innovation performance is to modify the NPD framework. Because the design process is a succession of divergent and convergent phases, some researchers have proposed a strong divergence at the beginning of the process. This literature focuses on the front-end of the process, which includes a product concept statement and evaluation, product definition, and project planning (Khurana et Rosenthal 1998). The fuzzyfront-end of the NPD process is defined to include the stages prior to the actual development of a new product (Ozer 2007).Its performance, by first allowing for greater exploration and divergence at the beginning of the process, can lead to better NPD projects. The firms are able to move faster than their competitors and are more likely to introduce a winning product. "Well begun is more than half done," as stated by one of the practitionerswe interviewed. 
A similar but enhanced proposal can be found in the notion of concept shifting introduced by Seidel (Seidel 2007). Becauseinitial divergence is sometimes insufficient, it could be needed later in the process. This divergence is, indeed, the capacity to modify the initial concept and derive new concepts from it. The concepts and knowledge are all stored. This approach is a good answer to radical innovation contexts, which can pose considerable challenges to product development teams. Goals can be unclear and changing, and existing organizational processes may be inappropriate or not well developed. Product development team members initiate a changewhen a concept component is found to no longer fit with technical abilities or to no longer match emergent market needs.Initial concept components (stories, new vocabulary, and prototypes) in these radical innovation cases were employed to provide a starting point, not a complete product.

\section{A common framework to compare the two process models.}

To assess how these types of processes drive the exploration and control of an innovation breakthrough, we use a very simple, generic model of the design process (Hatchuel, Le Masson et Weil 2005). The design-spaces-value-management (DS-VM) model allows us to analyze learning and the control of convergence and is adapted to the design of products with high technical specifications. This modelis based on the notion of design space (DS), which is defined as a collective working space where designers can act in a way that enables them to learn about what they want to learn for their overall design process. The DSs refer to the learning phases; at the value management level, design spacesare designated (top-down arrow) and knowledge produced in design spaces (bottom-up arrow) is integrated. A development process appears as a sequence of DSs, each DS being derived from the VM layer and feeding the value management level in return. All the acquired results of a development process appear at the value management level, designed product(s) as well as acquired knowledge (new validated routines and competences, etc.).

In this framework, we can characterize the modular design process (see Figure 1 below). The architecture pre-exists, or it is considered to have been designed and validated inside a preliminary Design Space in charge of exploring "architecture" alternatives. Then, the design spaces for modular components are explored simultaneously. It clearly appears that product architecture structures value management; it supports the explorations and enables to integrate the results into product(s). Each modular component design space is in charge of organizing a good fit with changing external (e.g., market) conditions. The initial architecture cannot be revised once the architecture has been validated. In fact, there is a deep separation (represented by the vertical dashed line) between the "architecture" DS and subsequent steps. Turnover is not possible once the subsequent steps have been reached. Concept shifts are strictly impossible, as are even slight modifications of the architecture. 


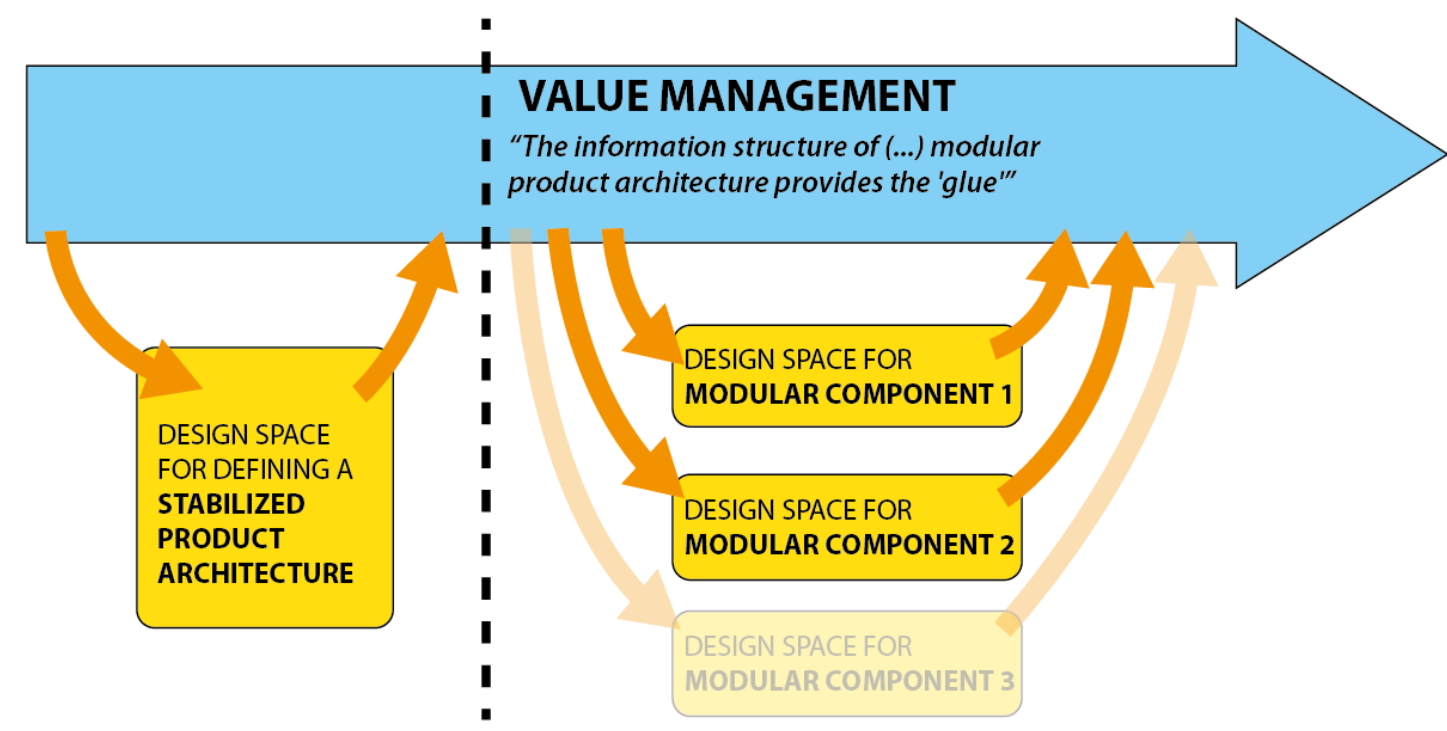

Figure 1: Model 1: DSVM model of modular design process

In the concept shift model, the DS can be simultaneously or sequentially explored. New concepts or variations of the initial concept are elaborated in design spaces and then integrated at the value management level. How are the design spaces designated? Seidel stated that concept shift occurs "when a concept component was found to no longer fit with technical abilities or match emergent market needs," which is rather imprecise. How does one make use of the knowledge acquired in a design space? As stated by Seidel, every concept is stored, which allows for large possibilities for exploration. However,one cannot be sure that the generated concepts will be useful and contribute to the VM of the full project if a new shift occurs. How can we control the direction, duration, and moment of exploration if the finding of new concepts is not serendipitous? In the concept shift model, these questions are left to further research.

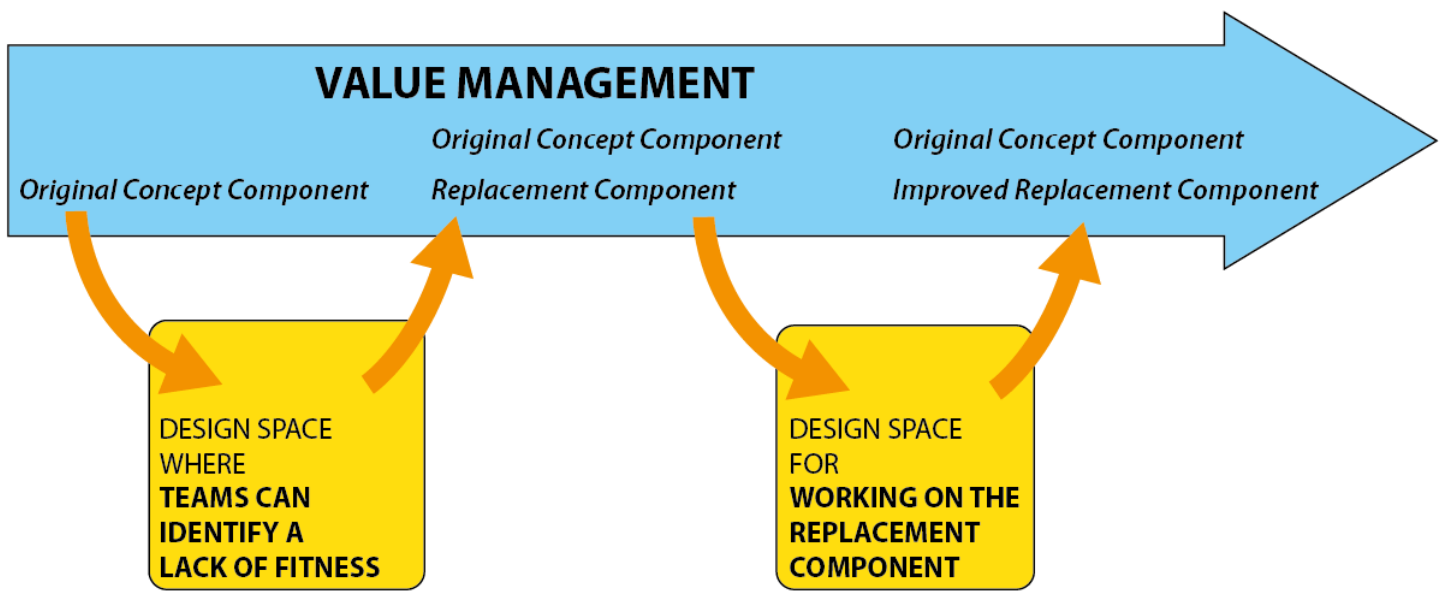

Figure 2: Model 2: DSVM model of the concept-shifting process

We now better understand the common issues and differences between the two models:

1- Common features: To combine exploration and control, the two models (modular design and concept shift) keep phases for explorations (modular component design or 
phases of concept exploration in the process) and describe an integration level (product architecture or concepts storage). In doing so, the two models considerably shift the perspective on radical innovation development processes:

a- Control is no more in the selection of the "best" alternative. It can also be in the designation of the appropriate "design space"- an appropriate design space for modular component development or appropriate design space for concept exploration. The control of exploration also consists in controlling the "divergence" quality. It is interesting to underline that this approach is in full coherence with the most recent advances in design theory and creativity cognition. These works have shown that managing innovative design processes actually consists in managing "de-fixation" (Archer 1965; Jansson et Smith 1991; Bonnardel et Marmèche 2004; Agogué et al. 2014; Le Masson, Hatchuel et Weil 2011). Instead of managing selection, the design process tends to manage efficient divergence.

b- Control is not necessarily in the convergence towards a final product. In the modular design process, several complementary modular components can result from the process (i.e., a family of products sharing a common architecture); in the concept shift process, several concepts are stored, and it is uncertain which concept will be finally successfully developed. The control of convergence can also consist ofaccumulating the knowledge acquired along with the explorations. Again, this convergence is in full coherence with recent advances in engineering design, which has long shown the importance of knowledge and competence accumulation to support the design process(Pahl et Beitz 2006), not only for "continuous innovation" but also for creativity (Cropley 2006).

2- Differences: Both models rely on specific conditions. In modular design, the product architecture is a key asset to support explorations and to integrate the results from these explorations. We can say that the modular design process relies on a "structural" condition. Incontrast, concept shift does not assume the structural stability of the product; it leaves "shifting ability" to process leaders and participants. This is a "leadership condition."

We can summarize these common features and differences in the table below, underlining the conditions that enable, in each model, the balance between exploration and convergence:

\begin{tabular}{|l|l|l|}
\hline Models & Modular & Concept shift \\
\hline Exploration & $\begin{array}{l}\text { Inside modular } \\
\text { components }\end{array}$ & Based on concept shift \\
\hline Convergence & $\begin{array}{l}\text { Inside an existing } \\
\text { architecture }\end{array}$ & $\begin{array}{l}\text { Based on the leader } \\
\text { capacities }\end{array}$ \\
\hline Condition & $\begin{array}{l}\text { A stable architecture } \\
\text { (hypothesis of structural } \\
\text { stability) that enables } \\
\text { (and limits) exploration }\end{array}$ & $\begin{array}{l}\text { A powerful smart leader } \\
\text { who balances } \\
\text { convergence and } \\
\text { exploration }\end{array}$ \\
\hline
\end{tabular}




\section{in modules}

Table 1: Synthesis of both models' capacities

It appear that the balance between exploration and convergence is based on limiting conditions. Still are these conditions really necessary? Can we find processes that don't meet the condition and still exhibit good exploration (Q1) and good convergence (Q2)? Let us now more precisely analysethe questions Q1 and Q2.

\section{Focus on the intensity of the breakthrough}

The first issueto be addressed in a major innovation process is the capacity to monitor the amplitude and direction of the wanted radical innovation breakthrough. This is a common feature of both models. In modular processes, the "architecture" enables the modular exploration; in concept shift, the actors are free to shift even late in the process.

Still, these two processes tend also to "limit" the monitoring of convergence by specific conditions. In modular processes, the breakthrough is framed and bounded inside the modules. The main and unbreakable constraint lies in the fixed architecture. In the concept shift process, the breakthrough is weakly driven because the link between concepts remains obscure, if not mysterious. This breakthroughdepends on the personal qualities of leaders and team members. Questions remain about their shared properties and the criticaldifferenceslikely to bring success to one or all of the concepts.

However, are these conditions really necessary? It seemspossible to manage richer, stronger, and more orientedbreakthroughs. In themodular model framework, it would be ideal to make a breakthrough innovation possible in the architecture not only within the components.In theconcept shift framework,the breakthrough is possible, but its amplification and the capacity to manage itwithin the concept-shifting model would be interesting. Therefore, our first research question is:

Q1: How can we monitor the amplitude and direction of exploration without necessarily relying on a stable architecture (Q1-a) or on leadership (Q1-b)?

\section{Focus on the convergence criteria of a radical innovation project}

In the modular model, the convergence is guaranteed by the architecture and the decoupling of the respective sub-systems. Everything that has been learned at a component level will be re-integratedwithin the global process due to the initial architecture phase.Inthe concept shift model,there is a strong accumulation of knowledge linked to the various explored concepts, but it is difficult or occasionally even impossible to identify what actually has to be stored. Value identification could be problematic. Therefore, our second research question is:

Q2: How can we organize a more cumulative convergence without necessarily relying on a stable architecture $(\mathbf{Q} 2-\mathrm{a})$ or on leadership $(\mathrm{Q} 2-\mathrm{b})$ ?

\section{METHOD}

Methodological approach: why case studies? 
We needed to exhibit two types of counter-examples:

1- On the one hand, we searchedfor a successful case to aid the discussion of the modular process model such that the product is known to such an extent that it leads the exploration (it supports the control of the exploration) but the architecture is not stable and is itself creatively redesigned during the exploration. This type of caseshows that the condition of structural stability is not actually necessary in this model. Such a case aids in the discussion of Q1-a and Q2-a.

2- On the other hand, we searchedfor a case to aid the discussion of the concept shift model such that the exploration is as free and diverging as in concept shifts but is built on well-identified exploration phases and accumulation processes. Such a case aids in the discussion of Q1-b and Q2-b.

Hence, we searched for two contrasting cases that ultimately illustrate very similar properties: Q1. monitoring the amplitude of exploration; Q2. organizing a cumulative process.

\section{Analytical framework}

We built our methodological frameworkon the DS-VM framework to investigate these questions. To answer Q1 and to qualify and track the explorations, we analyzed the device's input, outputs, and role in bringing innovation at the DS level. To answer Q2 and to qualifyaccumulation and convergence, we tracked the structure of the knowledge and the assessments made by the practitioners at the VM level. This work was facilitated by a new way of producing the data by directly tracing all numerical data generated by the CAD tools themselves.

\section{Data collection}

We decided to conduct two case studies (Yin 2003). We found highly relevant cases according to the aforementioned research gap and research questions. The cases we choseboth exhibit high and adequate levels of innovation, andthey generateda considerable amount of observable and unambiguous data because they mobilized an intensive use of CAD tools. Thus, their outcomes were easy to track. These data can be used to describe the entire design process in detail (the status of the concept, the exchanges between designers, and the mathematics describing the concept) andwere completed with several interviewswith designers.Each time, innovation was assessed with the interviews and collected materials. To clarify the type of toolsthat have been used and the type of data they produced, we provide a small explanation of their operating conditions here. Three types of CAD tools were mobilized for the two processes:

$-3 D$ modeling

These tools are used for the geometric modeling of an under-designed object. The designers typically design each individual part with the required level of precision before assembling all the parts, thus creating a full digital mockup of the soon-to-be product.

$-3 D$ simulation 
These tools are complementary to the above modeling tools. They are used to assess the geometrical properties of the 3D parts and assemblies, such as surface quality or resistance. They can also simulate ergonomics and almost every flux, such as thermal or magnetic.

\section{$-3 D$ development environment}

These tools are mostly used by the video game industry and for testing interactions. They consist of a set of building blocks or editing code lines, which set behaviors to virtual objects, such as 3D models or visualization options.

CAD tools are a new and powerful way of collecting data about the design process. They generate data and clarify the rules and mathematics of rules around which the designer designs and communicates. Unlike interviews, these data are not prone to subjectivity. They require a small amount of interpretation and deciphering, but they comprise very detailed and rich research material.

We also investigated physical mock-ups, which were of great use for simulating ergonomic constraints, particularly in the first case study.

To track the design process, we used three key features in each design space: 1) a strong focus was directed toward the starting constraints given to the designers and their degree of explicitness. 2) The device, namely, the different CAD tools used by the designersthat generated the data, was also within the scope of our tracking process. 3) Finally, the different results of the project are listed and expressed in terms of innovation and how we can characterize them. Regarding the value management level, we follow at each step the knowledge acquired until the step (the "known of the project") and the evaluation made by the designers at this step ("what the designers think about the current knowledge" - and what they consider as missing, unknown, desirable...).

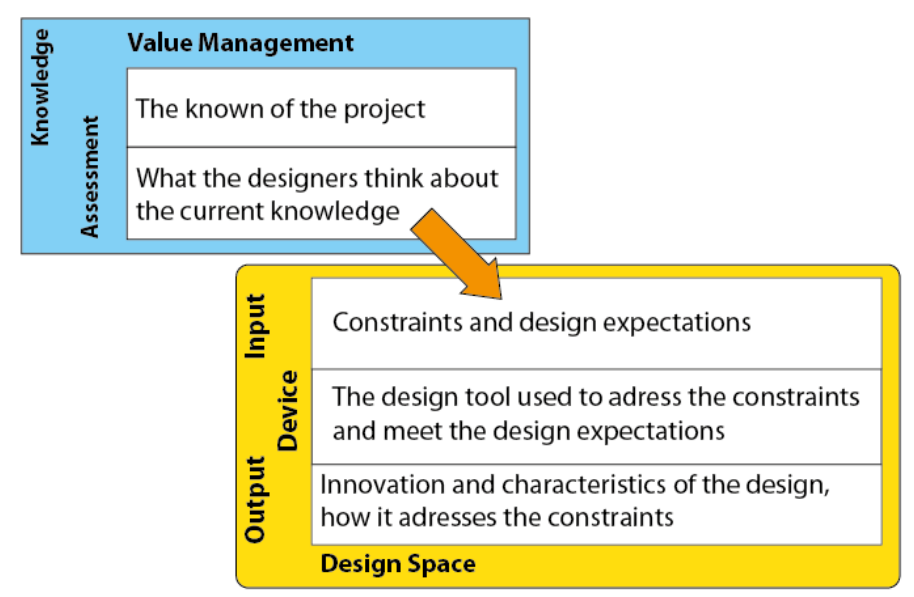

Figure 3: How the VM and DS layers were filled

\section{Choosing the cases}

The first case is similar to the modularmodel but proposes intensive architecture revision. The case is anespeciallysequenced project with identified design 
spaces and steps. The constraints were very clear and explicit. The designers faceddifficult constraints but managed to be very creative and original, obtainingunexpectedly good results. In a sense,this process was similar to a frontloading process(Thomke et Fujimoto 2000)distributed over the entire design process. The capacity of the tool to play with the right constraints was the key in this case and was successfully exploited by the designer during two critical steps of the design process. What could have been poor in terms of innovation due to the number of constraints, turned out to be both a success and an innovation due to the nature of the toolsused.

The second case is similar to the concept shift model but includes an accumulation of knowledge and a form of organized convergence. The caseis highly exploratory, and its success comes from unexpected directions. The starting brief was very optimistic and was linked to difficult constraints, but there were no tools suitable for handling them. Two designers, frustrated by the project's lack of progress and its probable imminent failure, reinterpreted some non-priority constraints by choosing the one most adapted to their favorite tools. In both cases, the designers were able to achieve innovation and success by working off the grid.Still the convergence was well controlled, and a new architecture was proposed for the initial project, stressing the cumulative capacity of the tools.

\begin{tabular}{|c|c|c|c|c|}
\hline Case & CAD tool used & Interviews & Data analyzed & Case features \\
\hline $\begin{array}{l}\text { Nooméo } \\
\text { '3D Scanning device' }\end{array}$ & $\begin{array}{l}\text { 3D modeling } \\
\text { 3D simulation } \\
\text { 3D vizualisation }\end{array}$ & 5 & $\begin{array}{l}\text { CAD models ( }>250) \\
\text { Physical Mock-ups } \\
\text { Presentations }\end{array}$ & $\begin{array}{l}\text { Close to modular } \\
\text { but with architecture revision }\end{array}$ \\
\hline $\begin{array}{l}\text { Beauty Company } \\
\text { 'Makeup cabin' }\end{array}$ & $\begin{array}{l}\text { 3D modeling } \\
\text { 3D simulation } \\
\text { 3D dev. environment } \\
\text { 3D vizualisation }\end{array}$ & 2 & $\begin{array}{l}\text { CAD models }(>400) \\
\text { Software protoypes } \\
\text { Patents }\end{array}$ & $\begin{array}{l}\text { Close to concept shift } \\
\text { but with accumulation }\end{array}$ \\
\hline
\end{tabular}

Table 2: Cases summarized

\section{CASE STUDIES}

\section{Case 1}

We investigated a project for the design of a new portative $3 \mathrm{D}$ scanner. The scanner is a highly technical object, but ergonomics and usage also play crucial roles. At the beginning of the project, the directors of a startup called Nooméo had made very powerful algorithmsable to transform images and position data into usable $3 \mathrm{D}$ information through signal analysis, i.e., they were able to generate highly precise and sharp dot clouds and then mesh themto form 3D objects. To create the best 3D scanner possible, they found the hardware material able to feed their algorithm with the greatest efficiency, making compromisesamong a reasonable calculation time, resolution, and cost.They picked up the components and assembled them inside a plastic body.At a conference, a famous industrial designer and head of the design studio at Dassault systems encountered the team and proposed collaboration between 
them and the design studio. The aim was to both propose a better product with a "sexier look" (revamping) and to have a good story to tell to illustrate the capacities of the in-house Dassault Systems software CATIA for design and collaboration. The constraints were strong and direct at the beginning of the project. The industrial designers of the team had to propose a new product while maintaining exactly the same technical parts and means of producing the outer case, i.e., plastic injection. This was case in which almost all the design was completed; there were little to no degrees of liberty left, and all that wasexpected from the designer was to make the product "look good".

The project appeared to be "over-constrained" and impossible to achieve. The breakthrough relied precisely on the capacity to combine apparently contradictory requirements. At the beginning of the project,the following technical and functional constraints were identified and transmitted to the design team:

1- Constraint 1. Global operating technical conditions. The product was supposed to be as light as possible, have good ergonomic features, and be able to emit the internally produced heat.

2- Constraint2. Ready-made technical parts, such as inertial sensors, cameras, a fan, a battery, electronic cards, and a processor.As previously explained, the technical parts were already known when the project began, and no modificationswere possible. They had given size, weight, and operating conditions.

3- Constraint 3. A specific manufacturing method. The plastic case of the product was supposed to be made from two symmetrical molds with a middle joint plan. The technique was to be plastic injection molding. The shape of the plastic case was also very important because it was the conveyor of the dissipated heat.

The industrial designers, Nooméo, and engineers used the CAD software CATIA. This software allowed for the management of the entire design process by offering specialized tools adapted to the specific design steps and professions.At first, it had been usedto quickly generate architectures and evaluate the ergonomics and technical consequences of the different respective configurations of the technical parts. With direct and intuitive manipulations, quick iterations were possible, and Nooméo and the engineers validated one of the architecture models proposed by the industrial designers in less than two weeks. In this first step, knowledge of potentially contradictory requirements was used to identify the key challenges in the product architecture. A design space was set up to be able to create multiple alternative product architectures, some of them leading to breakthrough in term of a combination of technical capacity, user-friendliness and lower cost level. 


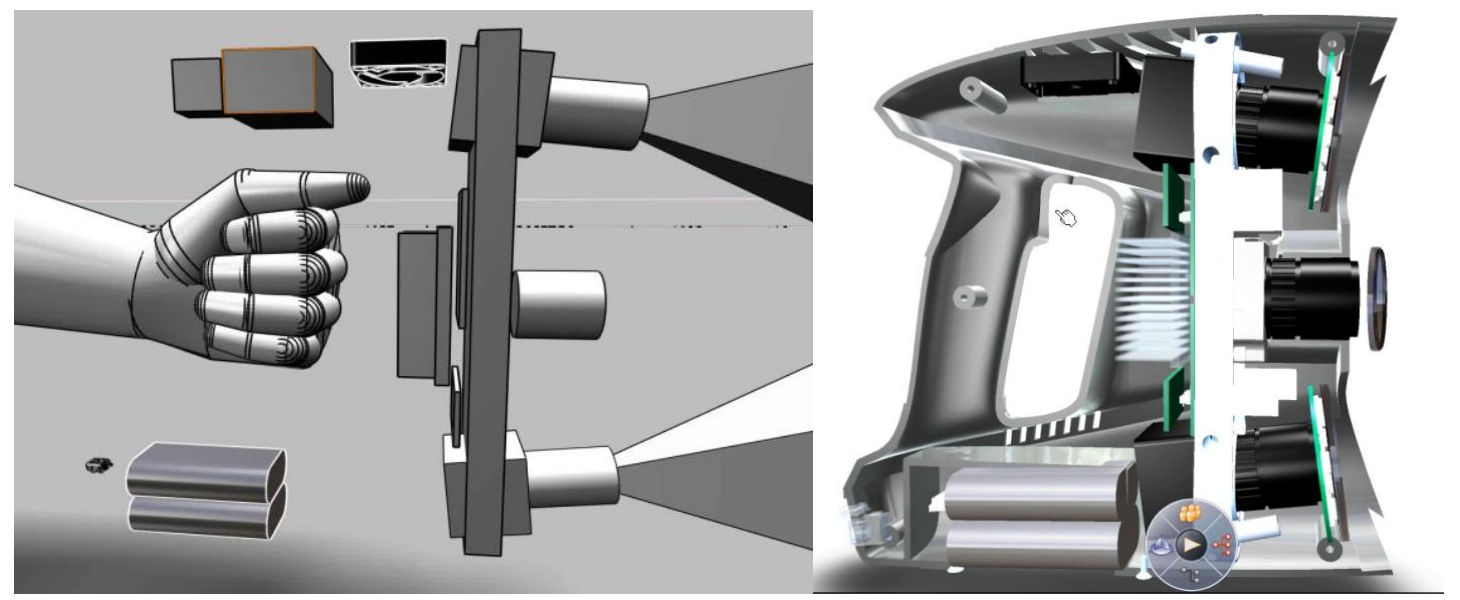

Picture 1: Architecture and outer case design and evaluation

Once the architecture was generated and validated with CATIA, the tool was used for thedynamic updating of different parts (e.g., foam addition, modification of thickness). The tool allows industrial designers to work on the shape of the object and,thus directly, to interact with its final appearance whilebeing able to control and assess the technical implementations. The software also guaranteed the designed plastic casecould be manufactured with the chosen technique (in this case, plastic injection). The main constraintwas the conformity of the modeled case with the clearance angle of the molding process and the optimization of its thickness according to the global/local thickness and weight.Throughout the process, it was possible to simulate the position of the future user's hand and thus optimize ergonomics (position of the center of gravity and minimization of the cantilever). The software also optimized the different airflows for the hot air exhaust grids relativeto the chosen styles.At one stage, there was a drastic revision of one of the important elements inside the case, andshock-damping foam was added to the optics-supported frame, increasing its size. The parameterized outer shape was automatically regenerated due to specific capacities of the software.

In the end, the project was a breakthrough because of its capacity to combine high user-friendliness, technological breakthrough and cost efficiency. The product's style is highly original compared with its competitors, due to itsnovel architecture. The product'sfluid lines and style were inspired by motorbikes, and yetit is comfortable enough to hold and provides a firm grip. The senior designersdeemed the product "beautiful and original". Cost efficiency and technical capability were very high by reusing available components and technologies. It has encountered great commercial success and is sold as part of a larger solution. 


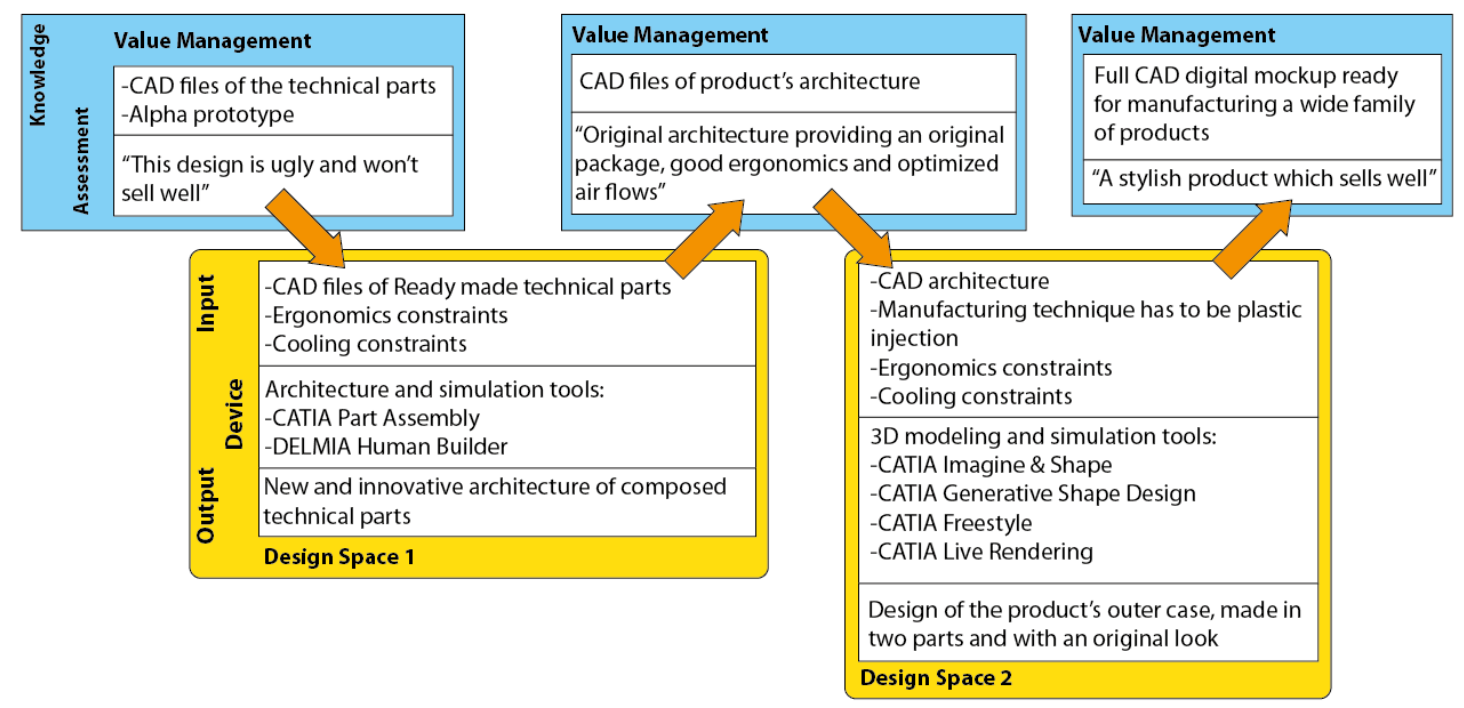

Figure 4: DSVM model for the first case study

\section{Synthesis}

In this case, Q1-a(the monitoring of the breakthrough without relying on a stable architecture) has been achieved by conducting the process in two identified steps. A sharp identification of the constraints led to the designation of two sequential design spaces to be able to deal efficiently with them, namely, the architecture and modeling of the outer case in a first step and the plastic case and the foam in the second step. Actually the designers take these constraints as an opportunity to generate breakthrough architectural alternatives. They are "generative constraints".

For Q2-a (cumulative convergence without relying on a stable product architecture), the convergence resultwas not on a single object, in contrast to what the pictures tend to show. Instead,the result wasthe set of all rules embedded in the CAD files, describing parts and the relationship between parts. Since all these elements are parameterized, it is possible to change parameters and, with the same set of rules, get a new product. Hence the result is a very rich and structured set of parameterized rules, that we can call an algebra of rules. This algebra can automatically give birth to several objects. Each combination of these rulescan give birth to an entirely different result that is still compatible with the initial brief.This algebra of rules enables the generation of a large amount of scanners, all of which integrate the same successful breakthrough. In fact, the final product, which could be mistaken for the result of the project, is only one of the multiple possible embodiments of the calculation of rules generated.

The process was tightly constrained and organized systematically. Itappears very similar to a "modular design process" in the sense that there are many known constraints at the beginning but, contrary to the usual modular process, the architecture is not stable. On the contrary, the exploration precisely focuses on architectural alternatives. This example, hence, shows that stable architecture is not necessary for a radical innovation process. What is necessary might rather be (Q1) the capacity to identify generative constraints and to be able to address the constraints in a 
creative way; and (Q2) the capacity to integrate the acquired knowledge into a structured set of rules.

Let usnow analyzecase 2 to examinewhether we find similar features despite strongly differing initial conditions.

\section{Case 2}

Our second case study is a project that started during a CEO meeting between a high executive of DassaultSystèmes and another high-level manager from a famous French beauty product company, which we will not cite for confidentiality reasons. The organization will be called "Beauty Company" from now on. The project was illdefined and was initially quite evasive and stressful in terms of technical requirements and functionalities, with very high or impossible expectations. The project was initiated as a distant vision and had no established business plan. It resembled a brand demonstrator. The process had considerable ramifications, and some steps were performed under non-official status. The project aimed to demonstrate the Beauty Company's beauty experience through a high-tech makeup booth. The experience booth was supposed to be designed and then prototyped for demonstration of the savoir-faire and qualities of the brand.The booth requirements were to propose a full beauty experience to the customer. The customer was supposed to enter inside the booth. Her face would be 3D scanned instantly and then displayed on a screen/mirror. An analysis would then be performed without touching her skin. Using light sensors, the image would simultaneously analyze several parameters of her skin, such as the dryness, sensitivity, pigmentation, and ranking on a wrinkled/tight scale. Then, she would receive beauty recommendations based upon the brand's products. Advice would also be given about how to use and apply the products on her skin. A real-time interactive preview of the final result would also be available.Several different organizations worked on the project: Beauty Company, the design studio, a prototypist, and a subcontractor. This original project had the following two constraints:

1- Constraint1. Highrequirements for hardware and software capacities (beyond the reach of current technologies) were implied for the realization of such a complex system, such asscanning, diagnostics, display, interface, realtime, and photorealistic.

2- Constraint2. The Beauty Company formulated a very specific and highly constrained use for the customer. The customer was supposed to have some time and be happy with the result, with a nice memory of the experience andpositive feedback about the brand. This use was implicit. The designers did not have the chance to explore this constraint.

Arange of technical parts and very specific software capable of extremely high levelperformances had to be designed to meet these constraints. The technical challenges were so high that technical modules were proposed but were not able to satisfy the required technical needs for the specific use case. In the end, the CAD software was only used to design the physical booth without the technical parts, i.e., only the walls, mirrors, and light positioning. The dispositive was able to address only 
a very small portion of the constraints. This inadequacy came from two sides. The constraints were not sufficiently exposed to the designers, so they could not answer them in a dedicated environment. Some constraints, such as the use case, were not considered as such and couldnot be addressed in detail with the software.

This first project sawlimited success with minimal or no innovation. The final result addressed a simplified use case, where the customer would enter the experience booth and receive makeup and counsel by a professional. The entire experience was recorded, and the customer could capitalize on the experience by taking home a personal DVD. In the end, however, this collaborative project had some unexpected side effects and results that are addressed below. Due to the motivation and creativity of two designers, two under-the-radar projects were conducted. The two designers, experts in their field, were able to use their expertise to redesign some key steps of the initial project by identifying critical constraints and using the more adequate workshops they found related to their own specific competencies. The results were astonishing, as they both developed highly innovative specifications.

This first sub-project proposed a replacement process for the design of new makeup. Traditionally, new makeup is created with a paper process in which "styles" are defined and different materials (which can be, for instance, powders or milks) are applied and tested to define a new range of corresponding makeup. The goal was to replace this process with a digital one. Instead of creating a style silhouette on paper, the makeup designer would use a real-time animated female 3D head on which he would apply digital makeup for visual assessment. At first, there was a capture step, which consisted of acquiring the visualization data of a given material. The process captured such properties as transparencies, reflections, and colors. Then, the designer was able to redesign the digital material inside the software, which mimics the properties of the original material in a virtual environment. These materials possess a large range of properties, such as transparencies, diffusion, reflections, and color information. Measuring these properties in real life and providing high-fidelity virtual correspondence is challenging.The technical constraints were numerous, and some of them were answered by external service providers, such as for the model of the human head. The designer addressed the following constraints:

3- Constraint3. Real-time implementation of makeup with photorealistic rendering.

The assessment was made by the subjective perspective of a highly competent makeup professional (Beauty Company style director).

This constraint implied a process for capturing the visual properties of the makeup and displaying them at will on a virtual head. This type of software is called a "sand box" and enables rapid and user-friendly interactions. A user can generate, edit, and interact with content of any type in $2 \mathrm{D}$ and 3D.Due to the very high plasticity of the software, the designer was able to test and validate a new process for creating materials inside a CAD tool. This method is now patentpending and will be used with the future tools of DassaultSystèmes. A user will be able to simply import and modify the properties of the materials being used inside the virtual world with intuitive and direct interactionsfitted to his or her knowledge and expertise, dependentupon 
whether he or she is an engineer or industrial designer. The tool for recreating the materials shouldalso be a good support for designing new materials or fine-tuning existing materials. The designer, due to the interactive environment, was able to test and evaluate new implementation methods under the shape of a dedicated modular architecture. This capacity was a great achievement of the project and is now being implemented as a reference tool and method for creating materials in the company leader CAD software.

Another sub-project was conducted by one of the industrial designers on the side of the official project. Whereas the efforts were focused on answering nearly impossible technical constraints, he identified the makeup action as an act of tremendous importance. In fact, applying makeup is difficult and requires special skills and use of specific tools. For instance, different pencils are used with different profiles for nail painting (sometimes up to three pencils for a specific work, with functional differences, e.g., a large pencil for quickly covering large areas and a thin pencil for detail). The designer worked on the following constraint:

4- Constraint 4. A single tool that address multiple types of makeup applications.

Exploring this constraint, the designer proposed an all-in-one pencilable to modify its profile at will to fit all the different steps of applying makeup.The given constraint is related to the makeupapplication process, which is complex and implies numerous different tools, occasionally of the same type, such as pencils.

The designer was able to design and assess the properties of a physical product able to operate as he had in mind, as a single pencil able to modify its profile at will to fit the needs of the user. The softwareallowed for the rapid assessment of technical solutions and the production of a reference 3D model, which was used to create an operational prototype.This new type of profile-changing pencil was patented (WO2009063305-A1).

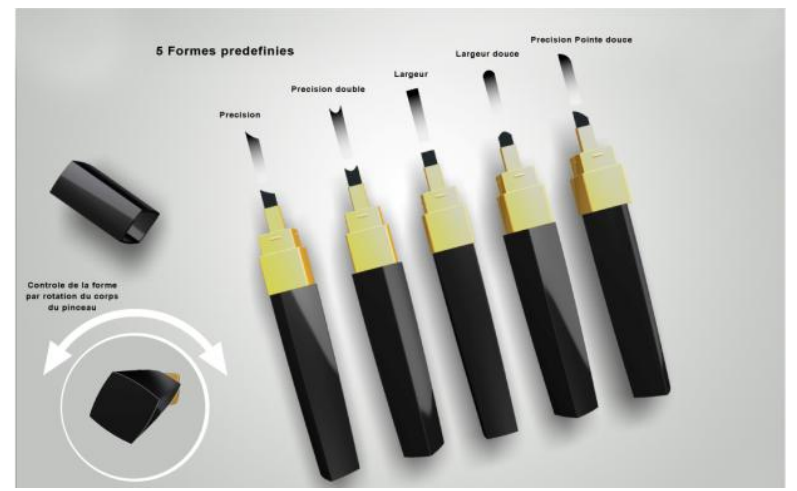

Picture 2: The patented polyshape pencil 


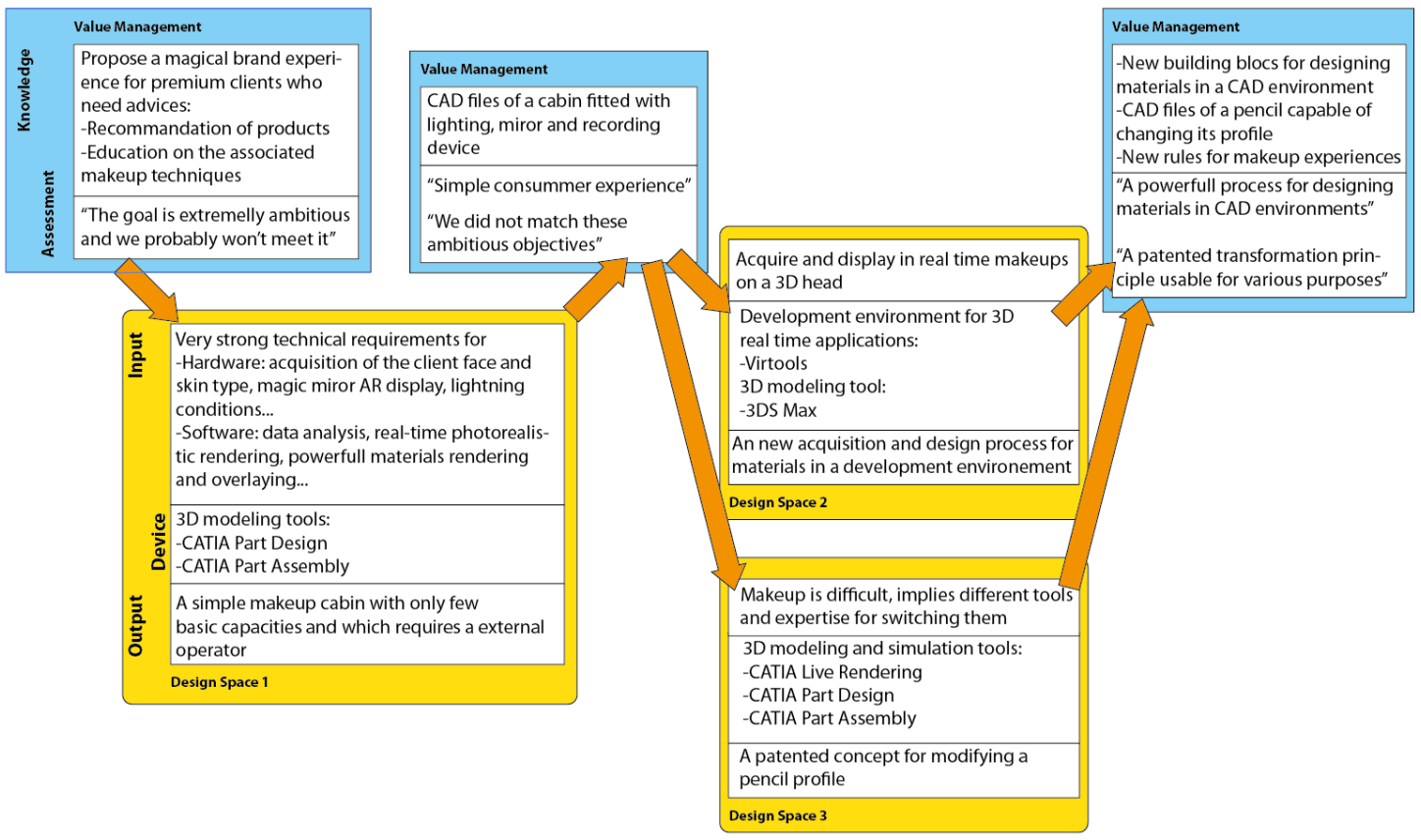

Figure 5: DSVM model for the second case study

This case study illustrates that design tools play a crucial role even in very explorative, ill-defined processes. The tools allows for integrated innovations. This success relies in large part on the possibility of the industrial designers to access and work on the constraints with the dedicated tools. The project is more likely to fail when this relationship is not possible. With its capacity to address many different issues inside a similar environment, build various designs, and address numerous professions, the CAD tool appears ideal to answer this challenge of linking constraints and specific design spaces. The process is very exploratory and similar to a concept shift, but we also identified a modularity approach embedded and hidden within this process.

\section{Synthesis}

At the first step, this case appears as a counter-example because neither a breakthrough normonitoring was achieved. Indeed in this first step, the constraint was poorly designated (especially as itrelated to the makeup use), and the associated DS was poorly identified. The result was disappointing in terms of breakthrough, but it did provoke a socialization of the issues because twodesigners, using their own personal initiative and the knowledge gained in this first, unsuccessful trial, identified sub-constraints and how they could address them in specific Design Spaces.

Regarding Q1-b(monitor exploration without relying on leadership and team members), the monitoring on the constraint in each sub-case was associated with a device for breakthrough, the two specific CAD tools. The identification ofthe constraints and the appropriateDS to addressthese constraintsfinally lead to breakthroughs. Once again, we see a clear logic of "generative constraint", addressed in the relevant design space (the constraint was "provided" by the analysis of the situation and the design space was based on CAD software). 
Regarding to Q2-b (cumulative convergence without relying on leadership and team members), just as in case 1, the main result is the structured set of rules for the generation of new makeup tools and the generation of an infinite amount of textures. Here, the cumulative convergence again takes the form of an "algebra of design rules", i.e., a set of rules that can be combined (to design multiple products). Moreover the tools and the makeup textures can easily be combined into new products and services.

Finally, this second case enriches the concept shift approach. There are clear concept shifts, and the team member initiative is clearly a key resource to support this shift. It also appears that the success is also linked to a capacity to identify and handle "generative constraints" (Q1) and to accumulate the acquired knowledge into a structured set of rules (Q2).

\section{RESULTS, DISCUSSION AND MANAGERIAL IMPLICATIONS}

We have shown that contemporary approaches to radical innovation processes finally have in common an ability to monitor exploration and to organize a cumulative convergence. However, we have also noticed that these approachestend to rely either on a stable product architecture (hence restricting exploration), or on leaders and team members. We use two case studies to discuss these restrictive hypotheses and to generalize two critical properties of radical innovation processes: R1 (for Q1), monitoring exploration actually relies on identifying and dealing creatively with "generative constraints"; and R2 (for Q2), cumulative convergence cannot be understood at the product level, but itoccurs as the constant evolution of a structured and coherent set of rules, an algebra of design rules that can be combined to form multiple products. Let us present these results in more detail.

Regarding the first research question, in both cases the exploration dependedupon two conditions: 1) clear identification of critical constraintsand 2) these constraints were associated with the appropriate device (architecture and design CAD tools) for a deep exploration of possible, relatedbreakthroughs.It is critical to link the constraints and the device to address them. The designer, being able to explore the space of alternatives to address the constraints, can finally design appropriate and original features. This device transforms the constraints into "generative constraints". This logic of "generative constraint" is widely known and used by artists and industrial designers (Arrighi, Le Masson et Weil 2014). It is actually also well known in contemporary engineering design methods,such asparameter analysis (Kroll 2013). In our study, it appears as a key feature of the management of radical innovation process. Interestingly, dealing with generative constraints leads to original design, and because this original design helps to address critical constraints, one is led to assume that originality is "acquired" for the rest of the process. We propose to call"acquired originality" a property that has been designed with the quality of being simultaneously original and satisfying a specific constraint.

Result 1: In radical innovation process, exploration can be monitored by identifying critical constraints and handling them in a specific design space (i.e., 
with the right design devices)to explore the most original alternative ways to address these specific constraints. To monitor exploration, it is necessary to address generative constraints.

Some comments: this result is coherent with past results on modular design process and concept shift process. In a modular design process a stable architecture helps at the same time to identify specific constraints and to address them. In concept shift process, the initial concepts or the talent of leaders or team members precisely consist in identifying and dealing with the constraints. As shown by our two cases, this logic of generative constraint is also true in other processes where the architecture is unknown and the process is not driven by one smart leader.

Interestingly, the two aspects "constraint identification and constraint handling" cannot be separated. Identification alone is not enough, one also needs the tools to address the constraints; conversely, being able to address certain specific constraints is not enough because the critical constraints could require new design tools to be dealt with.

Regarding the second research question, in both cases and in the two models, the cumulative convergence was not associated to one specific product. The product(s) actually appear as the artifactualresult of the combination of design rules. Thus, the cumulative convergence precisely appears at the level of the set of rules.

At the beginning of the processes, the set of rules is either full of contradictions (see case 1) or incomplete; in both situations it is full of unknowns. The cumulative process consists in transforming the unknowns (ignorance or apparent contradictions) into a set of known (coherent, structured, combinable) design rules. This structured set of design rules can be called an algebra, in the sense that the rules can be combined just like elements of a mathematical algebra can be combined by addition or multiplication. For instance, this algebra of rules defines how different components are spatially positioned and defines the links between them. This algebra also defines every parameter of the individual parts and can be bound with other parts and mapped to an infinite number of solutions that all come from different parameterizations of the same algebra. For instance, in Case 1, adding a part inside the casing requires a modification of the case part. However, a curve can be parameterized by defining the casing attached to what is inside it. If the interior is modified, then the curve is automatically edited accordingly and thus generates a new casing. The setof all elements and all relationship rules is the output of the design process. Instead of designing a single product, the designers with CAD tools generate the building instructions compatible with a large number of parameterized products.

This logic of an algebra of rules is well known in engineering design, but engineering design tends to consider that the set of rules is given and stabilized at the beginning and the development process consists in using the stabilized set. We understand here that the radical innovation process actually prepares a renewed set of rules to be used by improvement and optimization development processes. 
Result 2: In radical innovation process, the cumulative convergence occurs at the level of the set of rules, which tend to become a structured set of combinable design rules, or an algebra of design rules.

Some comments: this result is coherent with past results on modular design process and concept shift process. Ina modular design process, the algebra is mainly structured by the product architecture. A stable architecture helps at the same time to identify specific constraints and to address them. In a concept shift process, the leaders or team members infer the set of design rules from the set of concepts. The logic of algebra of rules helps to analyze the quality of the cumulative convergence. If there is no algebra and coherence between the rules resulting from a concept shift process, then this process might not be converging. As shown by our two cases, this algebra of rules playing the role of cumulative convergence is not reserved to processes with stable architecture or powerful leader.

The research as some implications for the design of new design tools: we have underlined that identification and handle of constraints were inseparable. Because radical innovation processes might lead to work on unexpected constraints, new CAD tools might be necessary to deal efficiently with radical innovation processes. This can mean either a wider library of CAD tools or a radically new type of configurable $\mathrm{CAD}$ tools wherein designers might be able to design their own CAD workshop to address ad hoc generative constraints. Regarding the cumulative set of design rules, our results lead us to predict the emergence of new CAD integration systems that will be able to handle heterogeneous types of data to check the consistency of the set of design rules.

The research has also some implications for specific design professions, experts in exploration and creativity, like industrial designers:it has often been thought thatindustrial designers should interveneeither very early on (to increase initial originality) or in the late stages of the design process to improve aesthetics. Our research suggests that when provided with the right tools, industrial designers are particularly able to creatively address generative constraints. Hence, they can support radical innovation processes, even in over-constrained environments.

More generally, this research brings insight on the management of innovation processes: after a first generation of works that tended to oppose NPD processes (with controlled convergence and very limited exploration) to Innovation processes (with poorly controlled convergence and random (uncontrolled) exploration, the new generation of works proposed ways to combine control and convergence either through concept shift or through stable architectures. We have shown that there are other cases that explore the unknown in a controlled way and still don't correspond two either of the two models and we have shown that there are two critical features common to all cases: a focus on generative constraint and a logic of cumulative design rules. As a consequence these two features might generic to several processes where teams have to explore the unknown and still have to keep a rigorous control of the exploration. More generally it suggests that in creative processes, there might forms of control that support (and not impede) a rigorous cumulative exploration. It 
paves the way to discuss the notion of control, a basic notions in management science, a notion that was developed for types of action where unknowness and exploration were very limited; we see how this notion is reinvented to support collective action in the unknown.

\section{ACKNOWLEDGEMENTS}

We thank all the participants and designers from DassaultSystèmes and Nooméofor their consideration, their efforts and their willingness to explain their data and answer the multiple questions asked during the interviews. 


\section{BIBLIOGRAPHY}

Agogué M, Kazakçi A, Hatchuel A, Le Masson P, Weil B, Poirel N, Cassotti M (2014) The impact of type of examples on originality: Explaining fixation and stimulation effects. Journal of Creative Behavior 48 (1):1-12.

Archer LB (1965) Systematic Method for Designers. Council of Industrial Design, London

Arrighi P-A, Le Masson P, Weil B (2014) Addressing constraints creatively: how new design software helps solve the dilemma of originality and feasibility". Creativity and Innovation Management Published on line Oct 2014.

Badke-Schaub P, Goldschmidt G, Meijer M (2010) How Does Cognitive Conflict in Design Teams Support the Development of Creative Ideas? Creativity and Innovation Management 19 (2):119-133.

Bonnardel N, Marmèche E (2004) Evocation Processes by Novice and Expert Designers: Towards Stimulating Analogical Thinking. Creativity and Innovation Management 13 (3):176-186.

Cheng Y-T, Ven AHVd (1996) Learning the Innovation Journey: Order out of Chaos? Organization Science 7 (6):593-614.

Christiansen JK, Varnes CJ (2009) Formal Rules in Product Development: Sensemaking of Structured Approaches*. Journal of Product Innovation Management 26 (5):502-519.

Christianson JK, Hansen A, Varnes CJ, Mikkola JH (2005) Competence Strategies in Organizing Product Development. Creativity and Innovation Management 14 (4):384-392.

Clark KB, Fujimoto T (1991) Product Development Performance : Strategy, Organization and Management in the World Auto Industry. Harvard Business School Press, Boston

Cooper RG (1994) Third-Generation New Product Processes. Journal of Product Innovation Management 11 (1):3-14.

Cooper RG, Kleinschmidt EJ (1993) Major new products: what distinguishes the winners in the chemical industry? . Journal of product innovation management 10:90-111.

Cropley A (2006) In Praise of Convergent Thinking. Creativity Research Journal 18 (3):391404.

Garud R, Kumaraswamy A (1993) Changing competitive dynamics in network industries: An exploration of Sun Microsystems' open systems strategy. Strategic Management Journal 14 (5):351-369.

Gawer A (ed) (2009) Platforms, Markets and Innovation. Edward Elgar, Cheltenham, UK and Northampton, MA

Harmancioglu N, McNally RC, Calantone RJ, Durmusoglu SS (2007) Your new product development (NPD) is only as good as your process: an exploratory analysis of new NPD process design and implementation. R\&D Management 37 (5):399-424.

Hatchuel A, Le Masson P, Weil B (2005) The Development of Science-Based Products: Managing by Design Spaces. Creativity and Innovation Management 14 (4):345-354.

Jansson DG, Smith SM (1991) Design Fixation. Design Studies 12 (1):3-11.

Khurana A, Rosenthal SR (1998) Towards Holistic "Front Ends" In New Product Development. Journal of Product Innovation Management 15:pp. 57-74.

Kroll E (2013) Design theory and conceptual design: contrasting functional decomposition and morphology with parameter analysis. Research in Engineering Design 24 (2):165183.

Le Masson P, Hatchuel A, Weil B (2011) The Interplay Between Creativity issues and Design Theories: a new perspective for Design Management Studies? Creativity and Innovation Management 20 (4):217-237.

MacCormack A, Verganti R, lansiti M (2001) Developing Products on "Internet Time": The Anatomy of Flexible Development Process. Management Science 47 (1):133-150. 
McDermott CM, O'Connor GC (2002) Managing radical innovation: an overview of emergent strategy issues. Journal of product innovation management 19 (6):424-438.

Ozer M (2007) Reducing the demand uncertainties at the fuzzy-front-end of developing new online services. Research Policy 36 (9):1372-1387.

Pahl G, Beitz W (2006) Engineering design, a systematic approach (trans: Wallace K, Blessing L, Bauert F). Springer, Berlin

Sanchez R (1995) Strategic flexibility in product competition. Strategic Management Journal 16 (S1):135-159.

Sanchez R, Mahoney JT (1996) Modularity, Flexibility, and Knowledge Management in Product and Organization Design. Strategic Management Journal 17 (Winter, Special Issue: Knowledge and the Firm):63-76.

Seidel VP (2007) Concept Shifting and the Radical Product Development Process. Journal of product innovation management 24 (6):522-533.

Sommer SC, Loch CH (2004) Selectionism and Learning in Projects with Complexity und Unforseeable Uncertainty. Management Science 50 (10):1334-1347.

Thomke SH, Fujimoto T (2000) The Effect of "Front Loading" Problem-Solving on Product Development Performance. Journal of Product Innovation Management 17 (2):pp. 128-142.

Ulrich KT, Eppinger SD (2008) Product Design and Development. 4th edn. Mc Graw Hill,

Utterback JM, Abernathy WJ (1975) A dynamic model of process and product innovation. Omega 3 (6):639-656.

Van de Ven A, Polley DE, Garud R, Venkataraman S (1999) The Innovation Journey. Oxford University Press, New-York, Oxford

Veryzer RW (1998) Discontinuous Innovation and the New Product Development Process. Journal of product innovation management 15:304-321.

Yin RK (2003) Case Study Research: Design and Methods. Applied Social Research Methods Series, Volume 5, 3rd edn. Sage, Thousand Oaks 